\title{
Case - Laparoscopic excision of the right testicular vein post- varicocele embolization and coil erosion
}

\author{
Bartosz Orzel, MD, MSc'; John-Paul McCarthy, MD'; Kenneth Rent, $M D^{2}$ \\ 'Faculty of Medicine, Dalhousie University, Halifax, NS Canada; ' 2 Department of Urology, Faculty of Medicine, Dalhousie University, Halifax, NS Canada
}

Cite as: Orzel B, McCarthy J-P, Rent K. Case - Laparoscopic excision of the right testicular vein post varicocele embolization and coil erosion. Can Urol Assoc J 2022;16(1):E51-3. http://dx.doi.org/10.5489/cuaj.7343

Published online August 26, 2021

\section{Introduction}

A varicocele is comprised of dilated and tortuous veins within the pampiniform plexus along the spermatic cord. ${ }^{1}$ Varicoceles are present in 35\% of men with primary infertility, ${ }^{1,2}$ and although the majority are asymptomatic, $10 \%$ of cases present with aching pain and scrotal fullness. ${ }^{3}$ Treatment is warranted with infertility or orchialgia. ${ }^{3}$ Varicocelectomy comprises ligating dilated spermatic veins, with multiple surgical approaches available. ${ }^{4}$ An alternative approach is varicocele embolization under radiological imaging using various occluding agents. Although minimally invasive with theoretically fewer complications, challenges include higher technical failure rates with varicocele recurrence and lower spontaneous pregnancy rates. ${ }^{2,4}$

\section{Case report}

A 36-year-old man presented to urology in another province with a history of chronic, dull, and mild right-sided orchialgia. He also experienced a mild, dull pain radiating into the right lower abdominal quadrant. Physical examination identified a right varicocele, while a scrotal ultrasound revealed a right spermatocele. It was suspected that the varicocele was responsible for the scrotal discomfort and right lower quadrant pain, and thus the patient underwent a right varicocele embolization with endovascular coils. Following the procedure, the patient began experiencing a progressively dull, increased in severity abdominal pain in the right upper quadrant. A subsequent spermatocelectomy alleviated his scrotal discomfort but he was left with the pervasive right upper quadrant pain.
The patient presented to our clinic in early 2019 with hesitancy, urgency, and several months of intermittent, gross hematuria. He also complained of a dull, mild-in-severity right flank pain that radiated to the groin, as well as a more severe (rated up to 10 out of 10 on a pain scale), deep, constant, and pervasive pain in the right upper abdominal quadrant that was present for nearly one year following the embolization procedure. Prolonged periods of standing produced episodic pain flares, impacting his ability to function at a correctional center. Examination revealed tenderness over the right costovertebral angle (CVA) and the right upper abdominal quadrant, with no abdominal nor intrascrotal masses palpated. His wife was pregnant at presentation.

Bloodwork and urinalysis were clear. A kidney, ureter, and bladder (KUB) X-ray revealed no nephrolithiasis, but did show the metallic coils in the right testicular vein postembolization (Fig. 1A). Computed tomography (CT), hematuria protocol, revealed no intra-abdominal abnormalities, nor evidence of inflammation (Fig. 1B). Cystoscopy was unremarkable. It was postulated that the testicular vein was in close proximity to the ureter and perhaps an erosion and fistula produced the hematuria; yet, bilateral retrograde pyelograms displayed that the coils were further from the right ureter than suspected (Fig. 1C). Although right ureteroscopy was challenged by tightness that prevented full passage of a ureteroscope, visualization of the ureter up to and beyond the level of the proximal coils revealed no upper tract abnormalities responsible for the hematuria. Finally, a scrotal ultrasound was unremarkable.

Although the patient's hematuria spontaneously resolved, the pain persisted. Conservative measures attempted included activity limitations, scrotal support, and anti-inflammatory drugs and opioids. These measures achieved inadequate pain relief, with four emergency department visits for pain flares over the course of one year. As other etiologies were excluded, coil removal became tenable. Interventional radiology was consulted regarding intravascular retrieval. However, the patient previously connected with men from online support groups who had similar experiences and whose pain was relieved following testicular vein removal. This compelled 

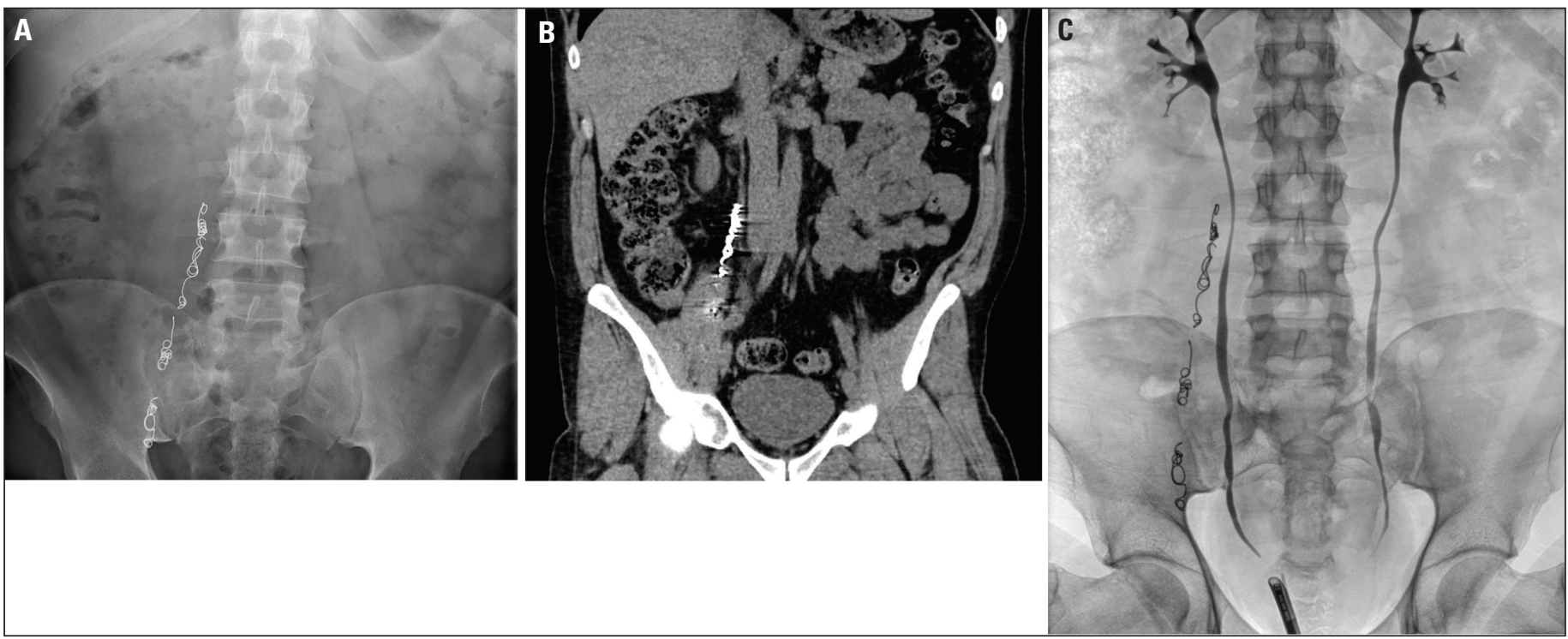

Fig. 1. Coronal images of the embolized right testicular vein with a (A) kidney, ureter, and bladder X-ray; (B) computed tomography with contrast enhancement; and (C) retrograde pyelogram. On retrograde pyelogram, it can be visualized that the endovascular coils are separate from the trajectory of the right ureter.

the patient to proceed with surgery, and we thus performed a laparoscopic excision of the embolized right testicular vein in early 2021.

Laparoscopy revealed a clean abdominal cavity without significant adhesions. It also became immediately apparent that the endovascular coils were eroding through the

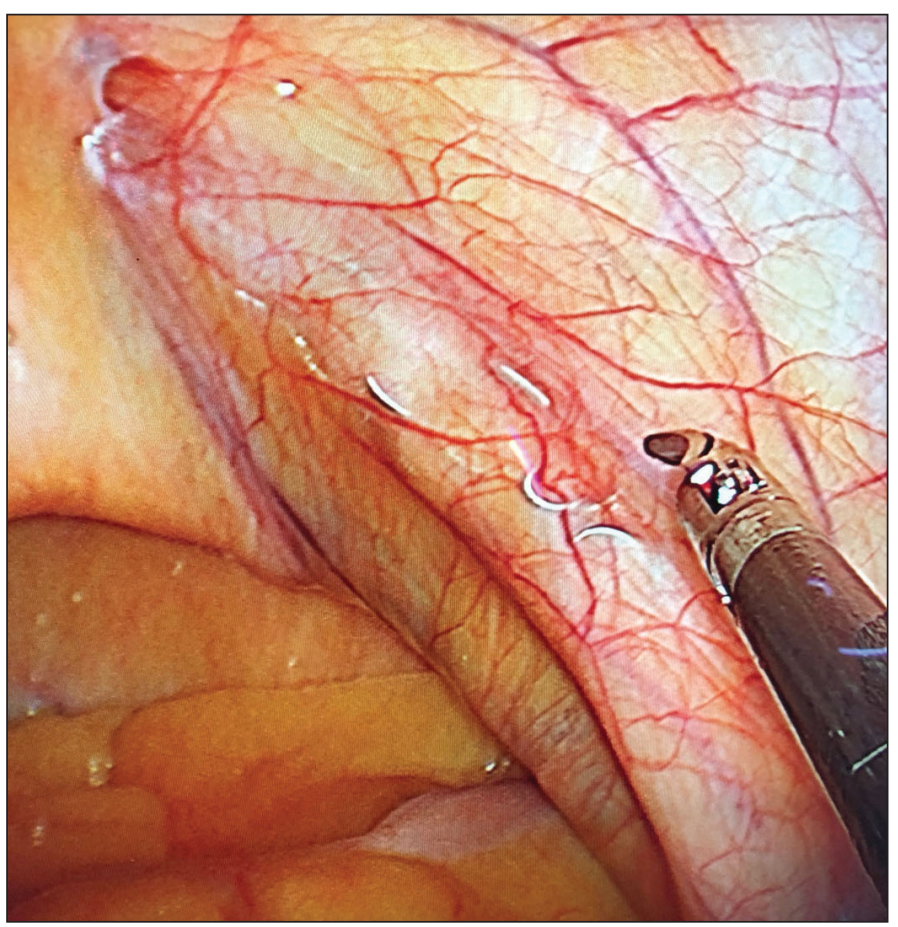

Fig. 2. Intraoperative imaging of the embolized right testicular vein down near the inguinal ring. During laparoscopy, the endovascular coils were seen to be eroding through the vein and the overlying peritoneum, yet, there was minimal inflammation and/or fibrosis along the course of the testicular vein. right testicular vein and the overlying peritoneum (Fig. 2). At around the mid-ureter, there was mild inflammatory and fibrous tissue present, which may have contributed to the resistance preventing proximal ureteroscopy. A ureterolysis was thus performed to safely mobilize the ureter. To ensure removal of all coils, the testicular vein was then dissected down to the deep inguinal ring, pulled $1 \mathrm{~cm}$ superiorly, and clipped a few $\mathrm{cm}$ distally from the nearest coils. The vein was then dissected up to the testicular vein ostium, and a non-coiled segment was clipped $2-3 \mathrm{~cm}$ superior to the most proximal coils. Once completely divided, the specimen was removed with an Endo Catch ${ }^{\text {TM }}$ pouch and was sent off to pathology (Fig. 3). There were no surgical complications.

Postoperatively, the patient reported that his flank and abdominal pain had completely resolved and that he felt pain-free for the first time since the embolization three years prior. The patient was discharged home the same day in minimal discomfort. At one-week followup, he reported a moderately achy, pulling discomfort in his right testis. No hydrocele was detected, and as venous congestion was suspected, he was prescribed a short-term course of Celebrex ${ }^{\circledR}$ and advised to ice his groin regularly. At one-month followup, he continued to have full resolution of his flank and abdominal pain, yet the scrotal discomfort persisted. This responded to a percutaneous nerve block with bupivacaine and methylprednisolone, upon which the patient resumed normal activities.

\section{Discussion}

Prolonged convalescence may occur following varicocele embolization. Complications can include coil migration, 


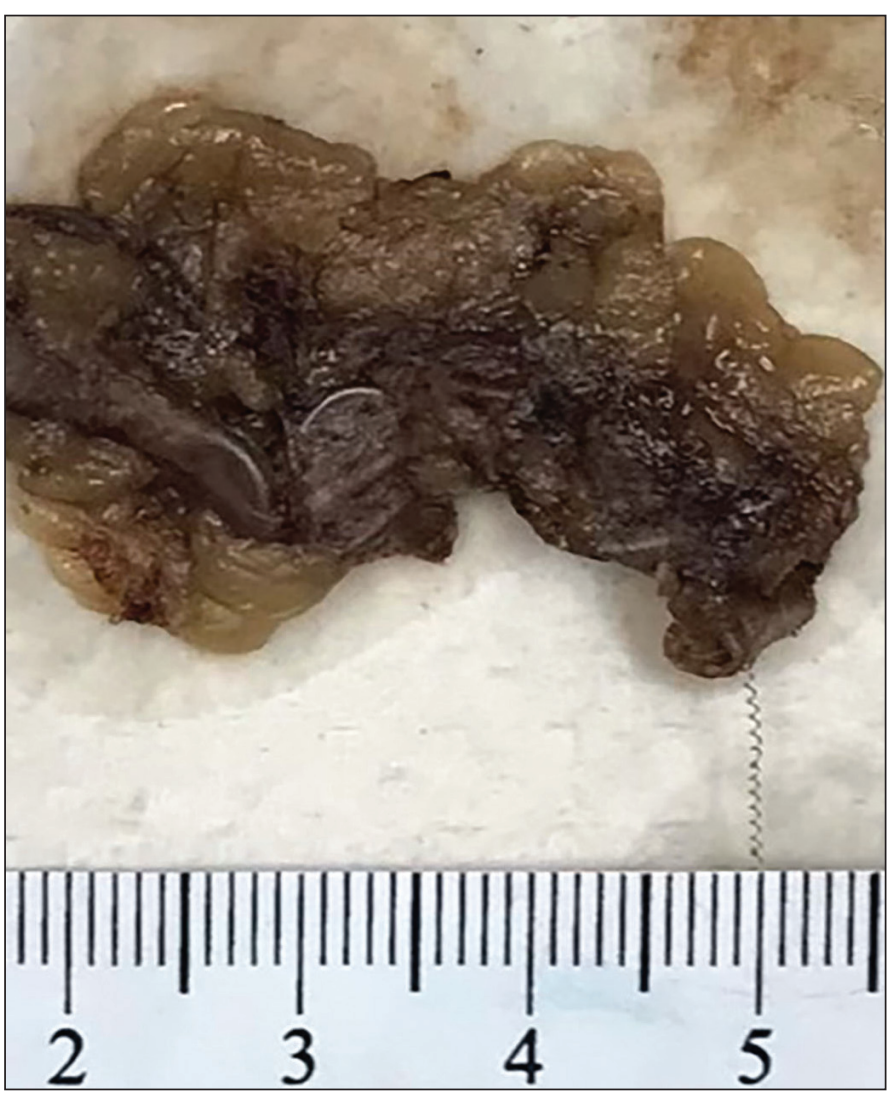

Fig. 3. Gross specimen of the excised, embolized, right testicular vein. The specimen consists of fibroadipose and vascular tissue with an overall measurement of $10.5 \mathrm{~cm} \times 2.0 \mathrm{~cm} \times 0.5 \mathrm{~cm}$. Centrally running almost the full length of the specimen is a metallic coil. No significant histopathological abnormality noted.

vascular perforation and contrast extravasation, hydrocele formation, and/or venous thrombosis. ${ }^{2,5,6}$ In a systematic review, only two studies discussed venous perforation and contrast extravasation following embolization. ${ }^{7}$ In one study, perforation of the testicular vein occurred during catheterization, with no difference in the mean pain level between groups with and without perforation. ${ }^{8}$ Conversely, our patient appeared to gradually experience coil erosion and chronic pain post-embolization, which may have occurred with bodily movements over time. ${ }^{6}$ Pathophysiology aside, this case report adds a major complication of varicocele embolization not previously reported in the literature.

Post-embolization complications can be managed with percutaneous retrieval of intravascular foreign bodies. Under local anesthesia and venogram guidance, transcatheter retrieval of embolic agents is accomplished using snares, retrieval baskets, or grasping forceps. ${ }^{9}$ Laparoscopic excision of the coiled testicular vein was perhaps serendipitously more appropriate in this case, as coil erosion may have resulted in vascular perforation during intravascular coil retrieval. Therefore, despite coil retrieval being less invasive and arguably more straightforward, the technique chosen will depend on the clinical scenario, patient preference, equipment available, and operator expertise.

Varicocele embolization is an ideal treatment for recurrent and/or persistent varicoceles after varicocelectomy. ${ }^{10,11}$ In one study of recurrence, venography revealed that most persistent varicoceles were secondary to a duplicated testicular vein. Subsequent embolization was successful in $100 \%$ of these patients. ${ }^{11}$ Thus, varicocele embolization has a clear role in the setting of varicocele recurrence. In the absence of this scenario, it may have lower success rates and equally significant complications, ${ }^{2,4}$ including the rare possibility of endovascular coil erosion. Ultimately, despite its demonstrable utility, physicians must exercise due diligence in patient selection and heed caution when performing varicocele embolization.

Competing interests: The authors do not report any competing personal or financial interests related to this work.

This paper has been peer-reviewed.

\section{References}

1. Masson P, Brannigan RE. The varicocele. Urol Clin 2014;41:129-44. https://doi.org/10.1016/i. ucl.2013.08.001

2. Halpern J, Mittal S, Pereira K, et al. Percutaneous embolization of varicocele: Technique, indications, relative contraindications, and complications. Asian J Androl 2016;18:234-38. https://doi.org/10.4103/1008$682 X .169985$

3. Owen RC, McCormick BJ, Figler BD, et al. A review of varicocele repair for pain. Transl Androl Urol 2017;6:S20-9. https://doi.org/10.21037/tau.2017.03.36

4. Cassidy D, Jarvi K, Grober E, et al. Varicocele surgery or embolization: Which is better? Can Urol Assoc J 2012;6:266-8. https://doi.org/10.5489/cuai.295

5. Cayan S, Shavakhabov S, Kadio lu A. Treatment of palpable varicocele in infertile men: A meta-analysis to define the best technique. J Androl 2009;30:33-40. https://doi.org/10.2164/jandrol.108.005967

6. Iaccarino V, Venetucci P. Interventional radiology of male varicocele: Current status. Cardiovasc Intervent Radiol 2012;35:1263-80. https://doi.org/10.1007/s00270-012-0350-z

7. Makris $G C$, Efthymiou $E$, Little $M$, et al. Safety and effectiveness of the different types of embolic materials for the treatment of testicular varicoceles: A systematic review. Br J Radiol 2018;91:20170445. https://doi.org/10.1259/bir.20170445

8. Heye $S$, Maleux $G$, Wilms $G$. Pain experience during internal spermatic vein embolization for varicocele: Comparison of two cyanoacrylate glues. Eur Radiol 2006;16:132-6. https://doi.org/10.1007/ s00330-005-2840-8

9. Gabelmann A, Kramer S, Gorich J. Percutaneous retrieval of lost of misplaced intravascular objects. AJR Am J Roentgenol 2001;176:1509-13. https://doi.org/10.2214/air.176.6.1761509

10. Badar Z, Rachun $M$, Farooq Z, et al. Varicocele embolization following failure of varicocelectomy: A case series and review of literature. J Ayub Med Coll Abbottabad 2016;28:826-9. https://pubmed.ncbi.nlm. nih.gov/28586606/

11. Jargiello T, Drelich-Zbroja A, Falkowski A, et al. Endovascular transcatheter embolization of recurrent postsurgical varicocele: Anatomic reasons for surgical failure. Acta Radiol 2015;56:63-9. https://doi.org/10.1177/0284185113519624

Correspondence: Dr. John-Paul McCarthy, Department of Urology, Faculty of Medicine, Dalhousie University, Halifax, NS Canada; i_p_mccarthy@hotmail.com 